\title{
Estimation of absorptivity of Earth-atmosphere system over the MENA areas
}

\author{
Ouassila Salhi*, Mohammed Diouri, Mohammed Amine Moussaoui, Ibtissam Marsli and Rajae Meziane. \\ ME Sciences, Physics Department, Atmospheric Physic Team Faculty of Science, Mohammed 1st University, Oujda.
}

\begin{abstract}
The developed Annual Columnar Radiative Absorptivity (ACRA19) model that describes, in annual mean, the terrestrial radiation balance of an atmospheric column, allows the determination of the various regional, absorption and reflection of solar and infrared radiation using 2018's annual data of eight sites in MENA region ( between $22 \mathrm{~N}-38 \mathrm{~N}$ ) of latitude obtained from AERONET and NASA POWER. The atmospheric thermal absorptivity (ATA) is very significant at high temperatures with an average of $0.85 \pm 0.1$ for $1020 \mathrm{~nm}$ and the atmospheric visible absorptivity (AVA) registers $0.36 \pm 0.06$ when the total optical depth observes its maximum linked to dust aerosol advection.
\end{abstract}

Keyword: Absorption, AERONET, Aerosols optical thickness, MENA, Insolation.

\section{Introduction}

The Absorption of solar and thermal radiation by the atmosphere and soil determines climate trends. Both radiative and non-radiative energy transfer between the surface, atmosphere, and space control climate change[1], [2]. Over the last few years, the climate of the Middle East and North Africa (MENA) experienced an increase in temperature and high dryness[3], make MENA one of the most prominent climate change "hot spots". This region is described by the sizeable hot desert climate with a high concentration of dust aerosols [4] that influence the radiative balance of the climate system by absorbing and scattering solar radiation and thermal infrared radiation [5]. The annual average temperature varies between $10^{\circ} \mathrm{C}$ and $50^{\circ} \mathrm{C}$. Concerning precipitation, most MENA regions receive about 100 $\mathrm{mm}$ (southern humid tropical climate part of the Mena) and over $900 \mathrm{~mm}$ in temperate zones, with a climate trend Bwh and Csa.

The global climate model aims to describe the behaviour of the climate by incorporating either physical laws or by more practical means. Those models are interested in studying the interactions between the atmosphere, the oceans, and the surface of the earth's.

The atmosphere continuously bombarded by solar, IR, V, and UV photons; some are dispersed in space by atmospheric gases or reflected from clouds or the surface of the Earth's; others absorbed by atmospheric molecules (primarily water vapour and ozone), aerosols, and clouds [6]. These absorptions affect the atmosphere to heat up. The SW photons reach the earth's surface and absorbed by it (about 46\%). Atmospheric gases (mainly carbon dioxide, water vapour, and ozone), clouds and aerosols, and the Earth's surface also emit and absorb infrared photons, which promote heat transfer between regions or the loss of heat in space.

In this work and for eight sites in the MENA area (Figure 1), we determine the various absorptivity of solar radiation by the atmosphere AVA, the surface s1, and the reflectivity of solar radiation $\mathrm{r} 1$, as well as the absorptivity of infrared radiation by the atmosphere ATA, using a simple model of terrestrial radiation balance (Figure 2).

\section{Instruments}

The based data of the AERONET network were used. The AERONET network is a ground-based remote sensing aerosol network for solar photometric measurements set up by NASA. The CIMEL brand photometer is used for AERONET measurements for eight wavelengths $(340,380,440,500,675,870,1020$ $\mathrm{nm}$ and $1640 \mathrm{~nm}$ ) in addition to a $936 \mathrm{~nm}$ water vapour band). It collects data on aerosol optical properties [7], such as the aerosol optical depth (AOD) [8]. We also used data from the Prediction of the World Energy Resources (POWER) project. This Project collects and analyses data on a large scale that is important to the renewable energy industries climate change and especially the solar and wind research such as the surface albedo (As), surface temperature (Ts) and insolation at the top of the atmosphere (Ri) (Table 3 ).

\footnotetext{
* ouassilasalhi1996@gmail.com
} 
Table 1. Site characteristics (AERONET)

\begin{tabular}{lllll}
\hline \multicolumn{1}{c}{ Sites } & Lat. & Long. & $\begin{array}{l}\text { Alt. } \\
(\mathrm{m})\end{array}$ & Clim. \\
\hline NA: & & & & \\
$\quad$ Ouarzazate & $30.92 \mathrm{~N}$ & $6.91 \mathrm{E}$ & 1136 & Bwh \\
Tamanrasset_INM & $22.79 \mathrm{~N}$ & $5.53 \mathrm{E}$ & 1377 & Bwh \\
Cairo & $30.08 \mathrm{~N}$ & $31.29 \mathrm{E}$ & 23 & Bwh \\
Tunis_Carthage & $36.83 \mathrm{~N}$ & $10.20 \mathrm{E}$ & 48 & Bwh \\
Tizi_Ouzou & $36.69 \mathrm{~N}$ & $4.05 \mathrm{E}$ & 200 & Bwh \\
ME: & & & & \\
Kuwait_university & $29.32 \mathrm{~N}$ & $47.97 \mathrm{E}$ & 306 & Bwh \\
$\quad \begin{array}{l}\text { Dushanbe } \\
\text { KaustCampus }\end{array}$ & $38.55 \mathrm{~N}$ & $68.85 \mathrm{E}$ & 706 & Bwh \\
\hline & $22.30 \mathrm{~N}$ & $32.74 \mathrm{E}$ & 11.2 & Bwh \\
\hline
\end{tabular}

\section{Global Energy Balance}

Climate is determined by radiative and non-radiative transfer of energy between the surface, atmosphere, and space. The greenhouse effect is described by the integration of solar radiation and the increase of terrestrial radiation at the earth's surface and atmosphere.

The energy balances at the top of the atmosphere and the earth's surface can be described (figure 2) by:

At the top of the atmosphere (1)

$$
R_{i}-R_{s r}-R_{L W \uparrow(T O T)}=0
$$

And At the surface (2) $R_{\text {sas }}+R_{L W \downarrow(B O A)}=R_{\text {srs }}+R_{e}+R_{\text {latent }}+R_{L W \uparrow(B O A)}$

$\mathrm{R}_{\mathrm{i}}$ : solar incident, $\mathrm{R}_{\mathrm{sr}}$ : solar reflected, $\mathrm{R}_{\mathrm{LW} \uparrow(\mathrm{TOT}) \text { : }}$ outgoing thermal at the top of the atmosphere, $\mathrm{R}_{\text {srs }}$ : solar reflected by the surface, Rsas: solar absorbed by the surface, $\mathrm{R}_{\mathrm{e}}$ : evaporation, $\mathrm{R}_{\text {latent }}$ Latent heat, $R_{L W \uparrow(\mathrm{BOA}) \text { : }}$ long wave UP at the bottom of the atmosphere $\mathrm{R}_{\mathrm{LW} \downarrow(\mathrm{BOA})}$ : long wave down at the bottom of the atmosphere.

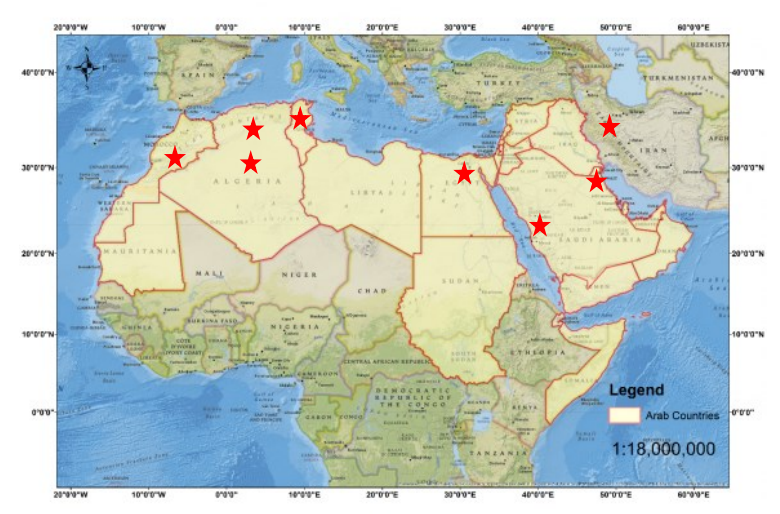

Fig. 1. Middle East and North Africa (MENA) map[7].

\section{ACRA19 Model}

The atmosphere represented by a "homogeneous glass layer" of temperature Ta, the absorptivity AVA in the visible spectrum and ATA in the infrared spectrum. The reflection $r_{1}$ of solar radiation by the atmosphere (clouds, aerosols, gas) is interpreted as follows: a fraction of the incident solar radiation $\mathrm{Ri}$ reflected in the space before entering the atmosphere, then receives a solar flux [9]:

$$
E i=\left(1-r_{l}\right) R i
$$

Ri: Average annual solar flux incident at the top of the atmosphere. The soil modelled by an opaque surface of temperature $\mathrm{Ts}$, absorptivity $\mathrm{s}_{1}$ in the visible spectrum equal to 1 in the infrared range. We assume that the absorptivity equals to the emissivity in the infrared range $\varepsilon_{\mathrm{a}}=\mathrm{a}_{2}$ and $\varepsilon=\mathrm{s}_{2}=1$ (Kirchhoff's law, extended to a spectral range). The system considered as in a radiative balance, the transfer of energy describe only through the radiative processes described above, and the associated irradiates are in the equilibrium everywhere. The physical quantities are annual observed averages that allow the inclusion of non-radiative processes.

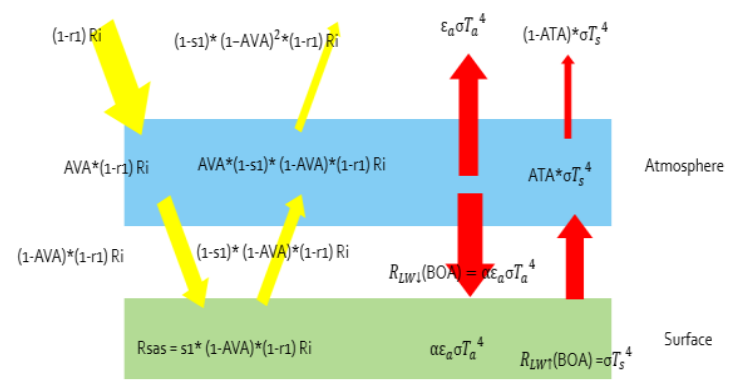

Fig. 2. Simple model of the greenhouse effect.

The study of the sensitivity concerning the model climate to two optical thicknesses of various wavelengths (500 $\mathrm{nm}$ and $1020 \mathrm{~nm}$ ). To determine the effect of atmospheric components [3] (Aerosols, take into consideration those of Rayleigh and absorption due to $\mathrm{O}_{3}, \mathrm{NO}_{2}, \mathrm{CH}_{4}$, and $\mathrm{H}_{2} \mathrm{O}$ ) also surface of the earth's on solar radiation and thermal fluxes. We developed a program that calculates the different absorption and solar radiation (Table 2).

Table 2. Optical variable descriptions

\begin{tabular}{cl}
\hline Symbol & Definition \\
\hline AVA & Atmospheric visible absorptivity. \\
ATA & $\begin{array}{l}\text { Atmospheric thermal absorptivity. } \\
\mathrm{s}_{1}\end{array}$ \\
& $\begin{array}{l}\text { Absorption of solar radiation by the } \\
\text { surface. } \\
\mathrm{r}_{1}\end{array}$ \\
& $\begin{array}{l}\text { reflectivity of solar radiation by the } \\
\text { atmosphere } \\
\text { emissivity of the atmosphere in the } \\
\varepsilon_{\mathrm{a}}\end{array}$ \\
$\varepsilon$ & $\begin{array}{l}\text { infrared } \\
=1 \text { emissivity of the earth's surface. } \\
\text { the ratio between the thermal radiation } \\
\text { emitted by the atmosphere downwards } \\
\text { and what is emitted upwards }\end{array}$ \\
\hline
\end{tabular}




\section{Results and discussion}

The absorption of SW and LW are deducted in the two panels, considering $500 \mathrm{~nm}$ (Figure 3.a) and 1020 $\mathrm{nm}$ (Figure 3.b), AVA ranges from 0.11 (Tunis Carthage) to 0.226 (Kuwait) with an average of $0.36 \pm$ 0.058 , while $r_{1}$ varies from 0.11 (Kuwait) to 0.27 (Tamanrasset). Absorption and reflection have asymmetric values; which explained by the atmosphere's composition (aerosols, clouds and gas) [10].
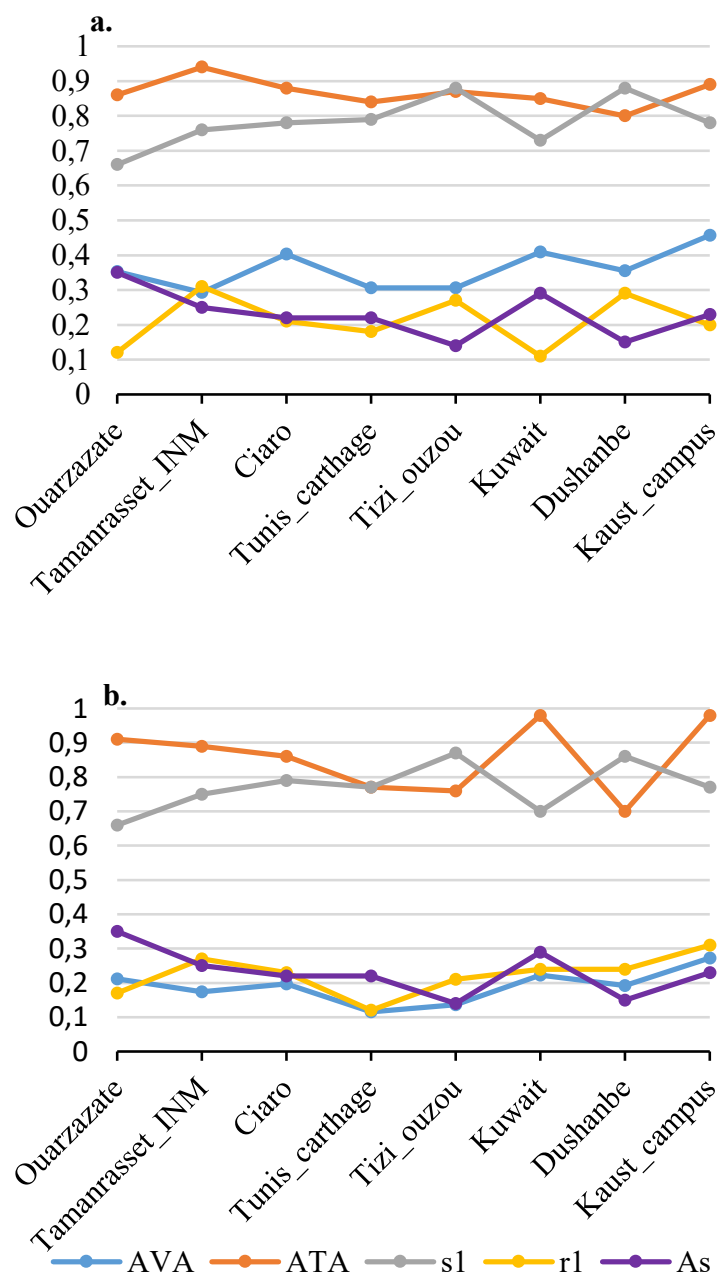

Fig. 3. Retrieved absorptivity of solar radiation by the surface $\left(\mathrm{s}_{1}\right)$, atmosphere (AVA) and reflectivity $\left(\mathrm{r}_{1}\right)$, and the absorptivity of infrared by the atmosphere (ATA); used As surface albedo (data from Nasa POWER) for 500nm (a) and $1020 \mathrm{~nm}$ (b). a.

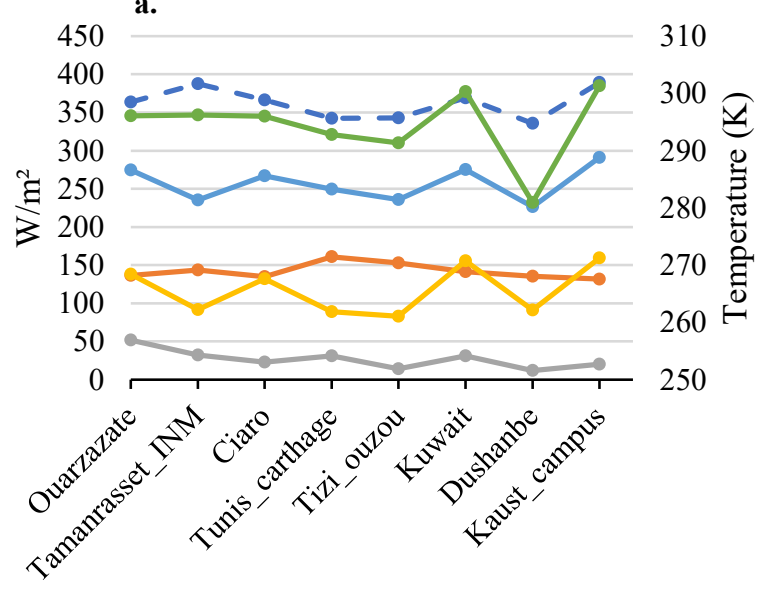

b. 310

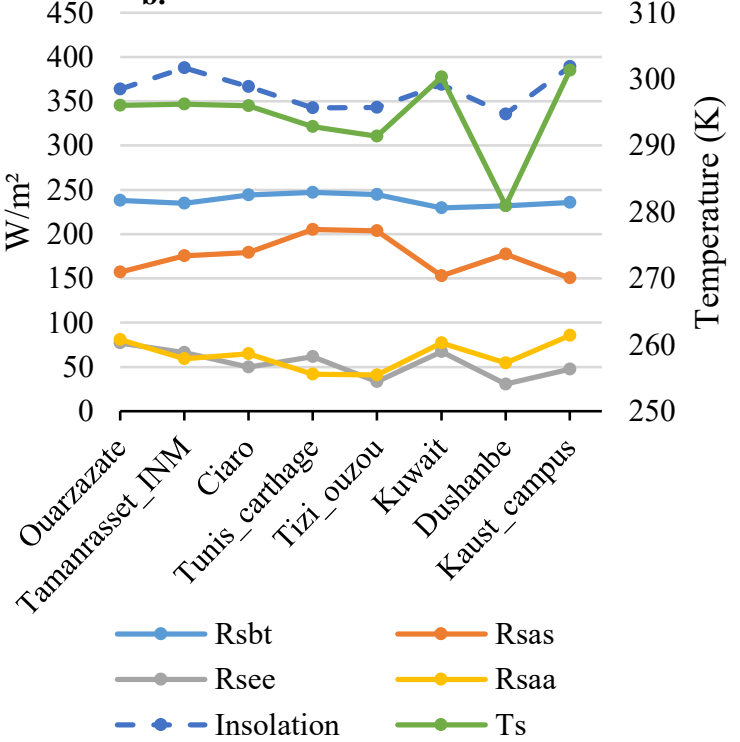

Fig. 4. Retrieved radiation flux (W.m ${ }^{-2}$ ) of Solar absorbed by the atmosphere (Rsaa), Solar absorbed by the surface (Rsas), and Total solar radiation absorbed (Rsbt), Solar radiation emitted outgoing (Rsee) and surface temperature (Ts), for 500nm (a) and $1020 \mathrm{~nm}$ (b).

ME region observe higher total optical depth TOD 0.51 for $500 \mathrm{~nm}$ (Cairo) and 0.61 (Kaust_campus) which explain the high absorption by the atmosphere AVA (Fig 3.a).

The significance of absorption confirmed by the small reflection values with a maximum of about 0.31 for Tamanraset INM. The absorption of solar radiation at $500 \mathrm{~nm}$ is higher than those at $1020 \mathrm{~nm}$, as can be shown (figure 4). Kaust_campus observes 0,45 as the

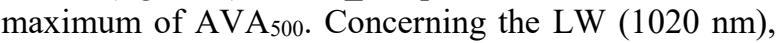
for AVA the average is around $0.19 \pm 0.049$, Tunis Carthage with the lowest value. For $\mathrm{TOD}_{1020}$ the absorption of solar radiation AVA (Fig 3.b) is low compared to $\mathrm{TOD}_{500}$. 
Table 3. Annual average of TOA insolation, surface temperature, surface albedo, AOD

\begin{tabular}{|c|c|c|c|c|c|}
\hline & \multirow{2}{*}{$\begin{array}{c}\text { TOA } \\
\text { Insolation } \\
\left(\mathrm{W} / \mathrm{m}^{2}\right)\end{array}$} & \multirow{2}{*}{$\begin{array}{c}\text { Surface } \\
\text { temperature } \\
\text { (K) }\end{array}$} & \multirow{2}{*}{$\begin{array}{l}\text { Surface } \\
\text { Albedo }\end{array}$} & \multicolumn{2}{|c|}{ Total Optical depth } \\
\hline & & & & $500 \mathrm{~nm}$ & $1020 \mathrm{~nm}$ \\
\hline Ouarzazate & 363.844 & 296.05 & 0.35 & 0,43 & 0,23 \\
\hline Tamanrasset_INM & 387.889 & 296.26 & 0.25 & 0,34 & 0,19 \\
\hline Cairo & 366.627 & 296.01 & 0.22 & 0,51 & 0,21 \\
\hline Tunis_Carthage & 342.449 & 292.82 & 0.22 & 0,32 & 0,12 \\
\hline Tizi_Ouzou & 342.99 & 291.38 & 0.14 & 0,36 & 0,14 \\
\hline Kuwait_university & 369.069 & 300.31 & 0.29 & 0,52 & 0,25 \\
\hline Dushanbe & 335.701 & 280.95 & 0.15 & 0,43 & 0,21 \\
\hline KAUST_Campus & 389.113 & 301.3 & 0.23 & 0,6 & 0,31 \\
\hline
\end{tabular}

According to the dust albedo $0.2-0.45$, with a high surface temperature, the variance of the surface albedo shows greater values for Ouarzazate and Kuwait. The minimum value for TiziOuzou is 0.15 . Figure 5 indicates that as As increases, the surface absorption $\mathrm{s}_{1}$ decreases.

The atmosphere's absorptivity of infrared ATA is important, with a maximum of 0.9 for Tamanarsset and an average of $0.86 \pm 0.04$ for $500 \mathrm{~nm}, 0.85 \pm 0.1$ for 1020 $\mathrm{nm}$. Dushanbe area has the lowest for both wavelengths.

Related to the latitudinal position that receives vast amounts of solar flux, the insolation at the top of the atmosphere of the different sites is about $362.21 \mathrm{~W} / \mathrm{m}^{2} \pm 20.40$. Figure 5 shows the solar radiation absorbed by the atmosphere range from $39.43 \mathrm{~W} \cdot \mathrm{m}^{-2}$ to $159.32 \mathrm{~W} \cdot \mathrm{m}^{-2}$ for all wavelengths. In terms of Rsaa, there is a difference between sites the MENA region's atmosphere directly contributes to the attenuation of incoming solar radiation by aerosols. Kuast_campus and Kuwait register the significant absorption with 0.61 as TOD for $500 \mathrm{~nm}$, absorption of solar radiation by atmosphere Rsaa increase up to $117.47 \mathrm{~W} / \mathrm{m}^{2} \pm 32$ for $500 \mathrm{~nm}$ and decrease, and reach $63.15 \mathrm{~W} / \mathrm{m}^{2} \pm 17$ for $1020 \mathrm{~nm}$.

The solar radiation absorbed by the surface Rsas shows a low variation between sites related to the moisture soil and desert; except for Tizi_Ouzou and Dushanbe (surface albedo $0.14-0.15$ ). Tunis_Carthage reaches the maximums $160.87 \mathrm{~W} . \mathrm{m}^{-2}$ and $205.23 \mathrm{~W} . \mathrm{m}^{-2}$ respectively to $500 \mathrm{~nm}$ and $1020 \mathrm{~nm}$. Rsee for $500 \mathrm{~nm}$ varies from $51.7 \mathrm{~W} . \mathrm{m}^{-2}$ at Ouarzazate to $11.89 \mathrm{~W} . \mathrm{m}^{-2}$ at Dushanbe is due to incoming solar and absorbed radiation.

Figure 5 shows the variations of the heat flux emitted by the earth's surface related to the surface temperature. In Dushanbe when the temperature is low, the emitted radiation is weak; contrariwise Kuwait and Kaust_Campus temperature about $26-27^{\circ} \mathrm{C}$ show high infrared radiation emitted. The desert of the MENA region considered as a hot spot of LW radiation when comparing the different absorption due to different TOD. The effect of optical depth is always in agreement with the absorption increase.
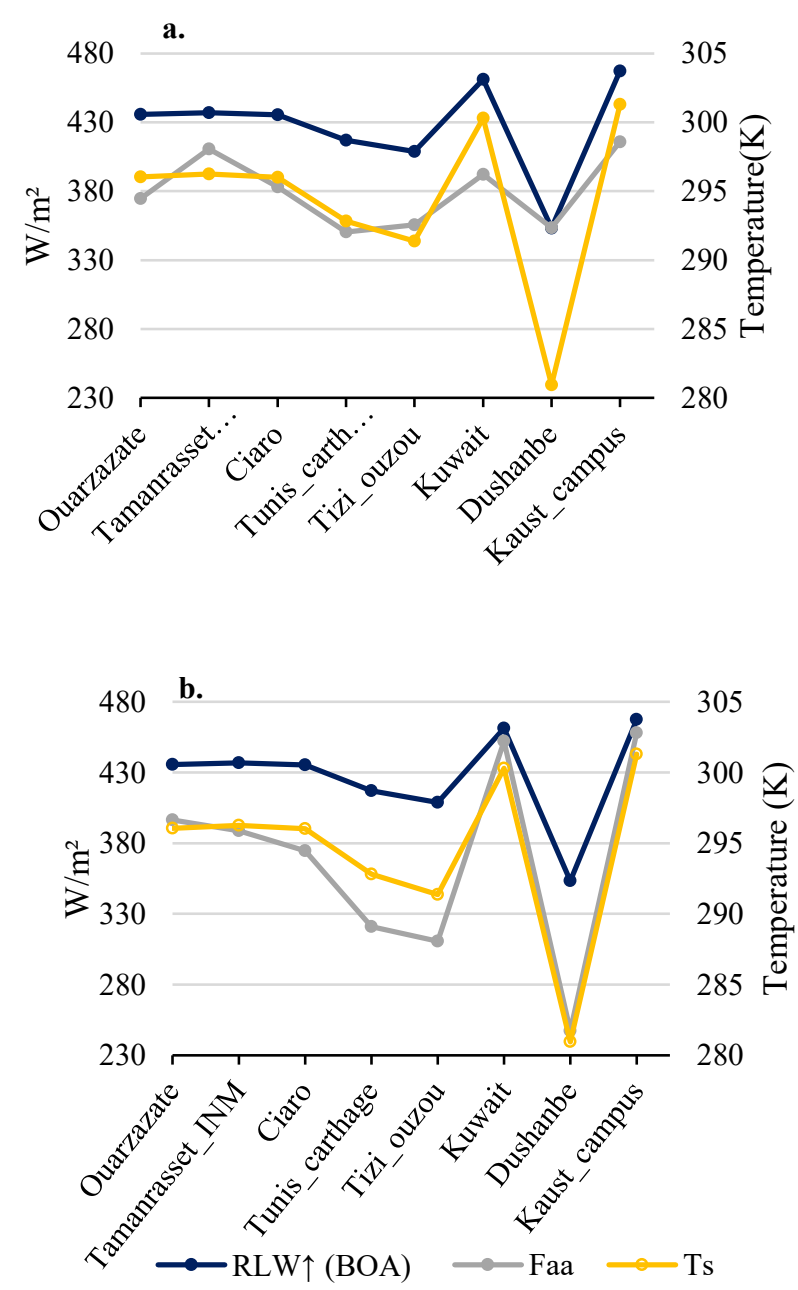

Fig. 5. Retrieved radiation flux $\left(\mathrm{W} \cdot \mathrm{m}^{-2}\right)$ : of emitted infrared by the surface (RLW $\uparrow(B O A))$, Absorbed Infrared by the Atmosphere (Faa) and surface temperature (Ts). For 500nm (a) and $1020 \mathrm{~nm}$ (b). 


\section{Conclusion}

The MENA region application of the developed Annual Columnar Radiative Absorptivity (ACRA19) model that describes, in annual mean, the terrestrial radiation balance of an atmospheric column, allows the determination of the various regional absorption and reflection of solar and infrared radiation. Based on 2018's annual data of eight sites, obtained from AERONET and NASA POWER. The MENA region receives a significant amount of solar flux. The absorption very important for both short wave AVA $(0.36 \pm 0.058)$ and longwave ATA $(0.85 \pm 0.1)$. The involvement of the different radiation, and the relationship between the up and down radiation fluxes indicates that sites with a high atmospheric SW absorptivity AVA register a low surface net absorption, a high temperature and a high infrared absorptivity ATA due to the essential thermal flux.

\section{References}

1. M. Diouri, Atmosphère et climat ... vers l'adaptation intelligente ., vol. I. Mohammed First University, Oujda, Morocco, 2018.

2. M. Diouri, Atmosphère et climat ... l'adaptation intelligente maintenant ., vol. II. Mohammed First University, Oujda, Morocco, 2020.

3. M. El-Nadry, W. Li, H. El-Askary, M. A. Awad, et A. R. Mostafa, « Urban Health Related Air Quality Indicators over the Middle East and North Africa Countries Using Multiple Satellites and AERONET Data », Remote Sens., vol. 11, $\mathrm{n}^{\circ} 18$, p. 2096, sept. 2019, doi: 10.3390/rs11182096.

4. G. Faour, M. Mhawej, et A. Fayad, « Detecting Changes in Vegetation Trends in the Middle East and North Africa (MENA) Region Using SPOT Vegetation ", Cybergeo, avr. 2016, doi: 10.4000/cybergeo. 27620 .

5. K. Constantinidou, P. Hadjinicolaou, G. Zittis, et J. Lelieveld, « Performance of Land Surface Schemes in the WRF Model for Climate Simulations over the MENA-CORDEX Domain », Earth Syst. Environ., vol. 4, no 4, p. 647-665, déc. 2020, doi: 10.1007/s41748-02000187-1.

6. G. Zittis et P. Hadjinicolaou, « The effect of radiation parameterization schemes on surface temperature in regional climate simulations over the MENA-CORDEX domain: WRF AS A REGIONAL CLIMATE MODEL OVER THE MENA-CORDEX DOMAIN », Int. J. Climatol., vol. $37, n^{\circ} 10$, p. 3847-3862, août 2017, doi: 10.1002/joc. 4959 .

7. O. Dubovik et M. D. King, «A flexible inversion algorithm for retrieval of aerosol optical properties from Sun and sky radiance measurements », $J$. Geophys. Res. Atmospheres, vol. 105, nº D16, p. 20673-20696, août 2000, doi: 10.1029/2000JD900282.

8. I. Marsli, M. Diouri, H. Steli, et A. El Khabbouti, « Optical characterization of cloud and aerosol of the temperate zone », Air Qual. Atmosphere Health, vol. 12, no 8, p. 969-981, août 2019, doi: 10.1007/s11869-019-00716-6.

9. A. Ben-tayeb, M. Diouri, R. Meziane, et H. Steli, «Solar radiation attenuation by aerosol: application to solar farms ", Air Qual. Atmosphere Health, vol. 13, no 2, p. 259-269, févr. 2020, doi: 10.1007/s11869-020-00790-1.

10. R. Meziane, M. Diouri, et A. Ben-tayeb, « Optical aerosol properties of megacities: inland and coastal cities comparison », Air Qual. Atmosphere Health, vol. 13, no 1, p. 25-33, janv. 2020, doi: 10.1007/s11869-019-00769-7. 